\title{
The Obesity Epidemic in the Veterans Health Administration: Prevalence Among Key Populations of Women and Men Veterans
}

\author{
Jessica Y. Breland, $P h D^{1,2}$, Ciaran S. Phibbs, $P h D^{1,2}$, Katherine J. Hoggatt, $P h D^{3,4}$, \\ Donna L. Washington, MD, MPH ${ }^{3,5}$, Jimmy Lee, $M S^{7}$, Sally Haskell, MD ${ }^{6,7,8}$, \\ Uchenna S. Uchendu, MD ${ }^{9}$, Fay S. Saechao, MPH' , Laurie C. Zephyrin, MD ${ }^{6,10}$, and Susan M. Frayne, \\ $\mathrm{MD}, \mathrm{MPH}^{1,2}$
}

\begin{abstract}
'VA HSR\&D Center for Innovation to Implementation (Ci2i), VA Palo Alto Health Care System, Menlo Park, CA, USA; ${ }^{2}$ Stanford University School of Medicine, Stanford, CA, USA; ${ }^{3}$ VA HSR\&D Center for the Study of Healthcare Innovation, Implementation \& Policy (CSHIIP), VA Greater Los Angeles Healthcare System, Sepulveda, CA, USA; ${ }^{4}$ Department of Epidemiology, UCLA Fielding School of Public Health, Los Angeles, CA, USA; ${ }^{5}$ David Geffen School of Medicine, University of California, Los Angeles, Los Angeles, CA, USA; 'United States Department of Veterans Affairs Central Office, Women's Health Services, Washington, DC, USA; ${ }^{7}$ West Haven VA, West Haven, CT, USA; ${ }^{8}$ Yale University School of Medicine, New Haven, CT, USA; ' United States Department of Veterans Affairs Central Office, Office of Health Equity, Washington, DC, USA; ${ }^{10}$ New York University School of Medicine, New York, NY, USA.
\end{abstract}

BACKGROUND: Most US adults are overweight or obese. Understanding differences in obesity prevalence across subpopulations could facilitate the development and dissemination of weight management services.

OBJECTIVES: To inform Veterans Health Administration (VHA) weight management initiatives, we describe obesity prevalence among subpopulations of VHA patients.

DESIGN: Cross-sectional descriptive analyses of fiscal year 2014 (FY2014) national VHA administrative and clinical data, stratified by gender. Differences $\geq 5 \%$ higher than the population mean were considered clinically significant.

PARTICIPANTS: Veteran VHA primary care patients with a valid weight within \pm 365 days of their first FY2014 primary care visit, and a valid height (98\% of primary care patients).

MAIN MEASURES: We used VHA vital signs data to ascertain height and weight and calculate body mass index, and VHA outpatient, inpatient, and fee basis data to identify sociodemographic- and comorbidity-based subpopulations.

KEY RESULTS: Among nearly five million primary care patients (347,112 women, 4,567,096 men), obesity prevalence was $41 \%$ (women $44 \%$, men $41 \%$ ), and overweight prevalence was $37 \%$ (women $31 \%$, men 38\%). Across the VHA's 140 facilities, obesity prevalence ranged from $28 \%$ to $49 \%$. Among gender-stratified subpopulations, obesity prevalence was high among veterans under age 65 (age 18-44: women $40 \%$, men $46 \%$; age $45-64$ : women $49 \%$, men $48 \%$ ). Obesity prevalence varied across racial/ethnic and comorbidity subpopulations, with high obesity prevalence among black women (51\%), women with schizophrenia (56\%), and women and men with diabetes $(68 \%$, $56 \%)$.

CONCLUSIONS: Overweight and obesity are common among veterans served by the VHA. VHA's weight management initiatives have the potential to avert long-term

Electronic supplementary material The online version of this article (doi:10.1007/s11606-016-3962-1) contains supplementary material, which is available to authorized users.

Published online March 7, 2017 morbidity arising from obesity-related conditions. Highrisk groups - such as black women veterans, women veterans with schizophrenia, younger veterans, and Native Hawaiian/Other Pacific Islander and American Indian/ Alaska Native veterans-may require particular attention to ensure that systems improvement efforts at the population level do not inadvertently increase health disparities.

KEY WORDS: veterans; obesity; health disparities; population health; women.

J Gen Intern Med 32(Suppl 1):S11-S7

DOI: $10.1007 / \mathrm{s} 11606-016-3962-1$

(c) Society of General Internal Medicine 2017

\section{INTRODUCTION}

A population health approach to preventing and treating obesity demands, as a first step, a sketch of the population served and its key subpopulations. High obesity prevalence is wellestablished in the general US population, ${ }^{1}$ as is obesity's association with numerous health risks, ${ }^{2}$ including high allcause mortality. ${ }^{3}$ Behavioral weight loss programs, medication, and surgery effectively treat obesity. ${ }^{2}$ However, to ensure that treatments are successfully implemented at the population level, descriptive epidemiological information is needed to identify those most in need of weight management and to inform the development of outreach programs. This is particularly important given known disparities in obesity prevalence, including the high prevalence among black and Hispanic women in the general US population. ${ }^{1}$

Compared to many US subpopulations, ${ }^{1}$ veterans using the Veterans Health Administration (VHA) have high rates of obesity. ${ }^{4}$ However, no recent analyses have leveraged the full capabilities of the VHA's administrative and clinical data to characterize obesity among the veterans it serves. Therefore, this paper describes obesity prevalence among almost five million women and men VHA veteran primary care patients, 
overall and across key subpopulations defined by gender, age, race/ethnicity, service-connected disability status, urban/rural residence, and period of military service, and among subpopulations with one of several physical or mental health conditions. Epidemiological findings from these rich national data will inform VHA weight management services and can be used to generate hypotheses regarding obesity and weight management in the general US population.

\section{METHODS}

Data Sources and Cohort. Using the Women's Health Evaluation Initiative (WHEI) Master Database (which includes outpatient, inpatient, and community care [fee basis] records, ${ }^{5}$ and VHA Vital Signs data for all women and men VHA patients), we identified all veteran patients nationally with at least one VHA primary care visit in fiscal year 2014 (FY2014). We included the $98 \%$ of these patients with nonmissing body mass index (BMI) data. (Information on veterans with missing BMI is in Online Appendix 1.) This program evaluation activity for VHA Women's Health Services and the VHA Office of Health Equity (OHE) received an official nonresearch determination from the national VA office of Women's Health Services, and therefore did not require review by the institutional review board.

BMI. To ascertain BMI, we developed an algorithm influenced by past work. ${ }^{6}$ In brief, we identified the closest non-missing weight taken within \pm 365 days of a veteran's first FY2014 primary care visit and the veteran's modal height between October 1999 and July 2016. We then created seven BMI categories: 1) underweight (BMI $<18.5 \mathrm{~kg} / \mathrm{m}^{2}$ ); 2) normal weight $\left(18.5 \mathrm{~kg} / \mathrm{m}^{2} \leq \mathrm{BMI}<25 \mathrm{~kg} / \mathrm{m}^{2}\right)$; 3) overweight $\left.\left(25 \mathrm{~kg} / \mathrm{m}^{2} \leq \mathrm{BMI}<30 \mathrm{~kg} / \mathrm{m}^{2}\right) ; 4\right)$ obesity-any (BMI $\geq 30 \mathrm{~kg} /$ $\left.\mathrm{m}^{2}\right)$; 5) obesity class I $\left.\left(30 \mathrm{~kg} / \mathrm{m}^{2} \leq \mathrm{BMI}<35 \mathrm{~kg} / \mathrm{m}^{2}\right) ; 6\right)$ obesity class II $\left(35 \mathrm{~kg} / \mathrm{m}^{2} \leq \mathrm{BMI}<40 \mathrm{~kg} / \mathrm{m}^{2}\right)$; and 7) obesity class III $\left(B M I \geq 40 \mathrm{~kg} / \mathrm{m}^{2}\right)$. See Online Appendix 2 for additional detail.

Key Subpopulations. We identified key subpopulations described in the VHA's Health Equity Action Plan, ${ }^{7}$ defined below, and, unless otherwise noted, assessed in FY2014 and based on WHEI and OHE algorithms, which are freely available online. ${ }^{5,8}$

Gender. Assessed as women or men.

Age on first day of FY2014. We included three age categories: 18-44 years, 45-64 years, and 65+ years.

Race/ethnicity. We included the following groups: white, black/African American, Hispanic, Asian, Native Hawaiian/ other Pacific Islander, American Indian/Alaska Native, multiracial, or unknown/declined to state.

Service-connected disability status. If an injury or illness is determined to have been incurred or aggravated during military service, it is considered service-connected; the Veterans Benefits Administration uses a multi-step process to rate its severity from 0 to $100 \%$. We used four categories: none, $0-49 \%, 50-99 \%$, and $100 \%$ (based on veterans' last ratings in FY2014).

Rural/urban residence. Veterans' last known addresses in FY2014 were used to define four categories: 1) highly urban (a metropolitan statistical area with 500,000+ residents), 2) urban $(50,000+$ people in the urban nucleus and at least 1000 residents per square mile in the urban core), 3) highly rural (county with $<7$ residents per square mile), and 4) rural (any other non-urban area).

Period of service. We grouped veterans based on their most recent period of military service, which is highly correlated with age: 1) Operation Enduring Freedom (OEF)/Operation Iraqi Freedom (OIF)/Operation New Dawn (OND), 2) Gulf War I/pre-OEF/OIF/OND, 3) post-Vietnam War/pre-Gulf War, 4) Vietnam War, 5) post-Korean War/pre-Vietnam War, 6) Korean War, 7) post-World War II, 8) World War II or earlier, or 9) unclassified. Years spanning eras can be found in Washington et al. ${ }^{9}$ A graphical representation is also available. ${ }^{10}$

Facility. We assessed obesity prevalence at each of the VHA's 140 facilities.

Comorbid physical and mental health conditions. Based on the presence of at least one instance of an ICD-9 diagnosis code in FY2014 outpatient or inpatient VHA or community care (fee-basis) data, we identified veterans with sleep apnea, diabetes, hypertension, lipid disorders, coronary artery disease, lumbosacral spine disorders, lower extremity joint disorders, major depressive disorder, bipolar disorder, posttraumatic stress disorder (PTSD), anxiety disorder, drug use disorder, alcohol use disorder, and/or schizophrenia. Conditions were chosen based on their strong association with obesity $^{2}$ and/or high prevalence among veteran populations. ${ }^{5}$

Analyses. We calculated frequencies across BMI categories within each subpopulation. We then repeated analyses, stratified by gender. This stratification was planned a priori because of known differences in obesity prevalence between women and men $^{11,12}$ and because, among VHA patients, women veterans tend to be younger, have greater racial/ethnic diversity, and have a higher burden of mental health comorbidity than men veterans. ${ }^{5}$ As in other OHE work, ${ }^{8}$ we highlight clinically relevant differences in the results, defined as $\geq 5 \%$ higher than the population mean, rather than reporting statistical tests of difference, which given our large sample could highlight small, clinically irrelevant differences. We used SAS Enterprise Guide 7.1 and SAS 9.2 software (SAS Institute Inc., Cary, NC) for UNIX and Linux.

\section{RESULTS}

The cohort included 4,914,208 VHA primary care patients (347,112 women, 4,567,096 men). Most veterans were either 
overweight or obese. Overweight prevalence was 37\% (women $31 \%$, men $38 \%$ ) and obesity prevalence was $41 \%$ (women 44\%, men 41\%; see Fig. 1). Across the VHA's 140 facilities, obesity prevalence ranged from $28 \%$ to $49 \%$ (see Online Appendix 3 for facility-level obesity prevalence by region). Below, we highlight key findings for obesity prevalence among subpopulations overall and stratified by gender (Table 1). See Online Appendix 4 for information on all BMI categories.

Overall Prevalence. Obesity prevalence was $\geq 5 \%$ higher than the population mean in some sociodemographic groups: veterans 45-64 years old (48\%), Native Hawaiian/other Pacific Islander veterans $(46 \%)$, American Indian/Alaska Native veterans (47\%), veterans with $50-99 \%$ or $100 \%$ service-connected disability status $(49 \%, 47 \%)$, and those who served in the Gulf War I/pre-OEF/OIF/OND (51\%) or just prior to the Gulf War (48\%) eras. Unsurprisingly, obesity prevalence was high among veterans with obesity-related conditions, and was highest among veterans with sleep apnea (72\%), diabetes $(57 \%)$, or lower extremity joint disorders $(50 \%)$. Obesity prevalence was also high among veterans with mental health conditions, particularly major depressive disorder $(48 \%)$, bipolar disorder (47\%), and PTSD (47\%), and among veterans with three or more conditions $(50 \%)$. In general, we saw similar findings across obesity classes (see Online Appendix 4).

Gender-Stratified Results. Obesity prevalence differed across age groups for women and men. Prevalence was highest among the middle age group (women $49 \%$, men $48 \%$ ), but there was a notable difference in obesity prevalence between women and men veterans age $18-44$ (40\% vs. 46\%). The prevalence of obesity was also notably high among black women $(51 \%)$, American Indian/Alaska Native men $(47 \%)$, and men veterans of unknown race/ethnicity (47\%). High obesity prevalence was also notable among women and men who served in the Gulf War I/pre-OEF/OIF/OND and postVietnam War/pre-Gulf War eras, and women Vietnam War veterans (Table 1).

With regard to physical health conditions, obesity prevalence was $\geq 5 \%$ higher among women than men for veterans with diabetes ( $68 \%$ vs. $56 \%$ ), hypertension (56\% vs. $46 \%$ ), and lipid disorders (52\% vs. $45 \%$ ). Gender differences in obesity prevalence among veterans with mental health conditions were modest, with the exception of schizophrenia, in which obesity prevalence was 15 percentage points higher among women than men (56\% vs. $41 \%)$. There were also gender differences among veterans with three or more conditions (women 54\%; men 49\%).

\section{DISCUSSION}

Among the almost five million VHA primary care patients in FY2014, 41\% were obese and 37\% were overweight, collectively accounting for most veterans seen in VHA primary care. Obesity prevalence was high compared to that of the general US population or military personnel, among whom obesity prevalence is estimated at $38 \%$ and $13 \%$, respectively. 1,13 However, comparisons must be interpreted with the understanding that VHA data reflect a treatment-seeking population, who may be older and sicker than the general population. ${ }^{14-18}$ Furthermore, while findings reflect the universe of veterans using VHA, they may not apply to veterans outside the VHA, who tend to be in better health. ${ }^{19,20}$ Nonetheless, high obesity prevalence, even among the youngest veterans served by the VHA, could partially explain why veterans who may be fit when leaving the military go on to develop more chronic conditions and poorer health than the general US population. ${ }^{14-18}$

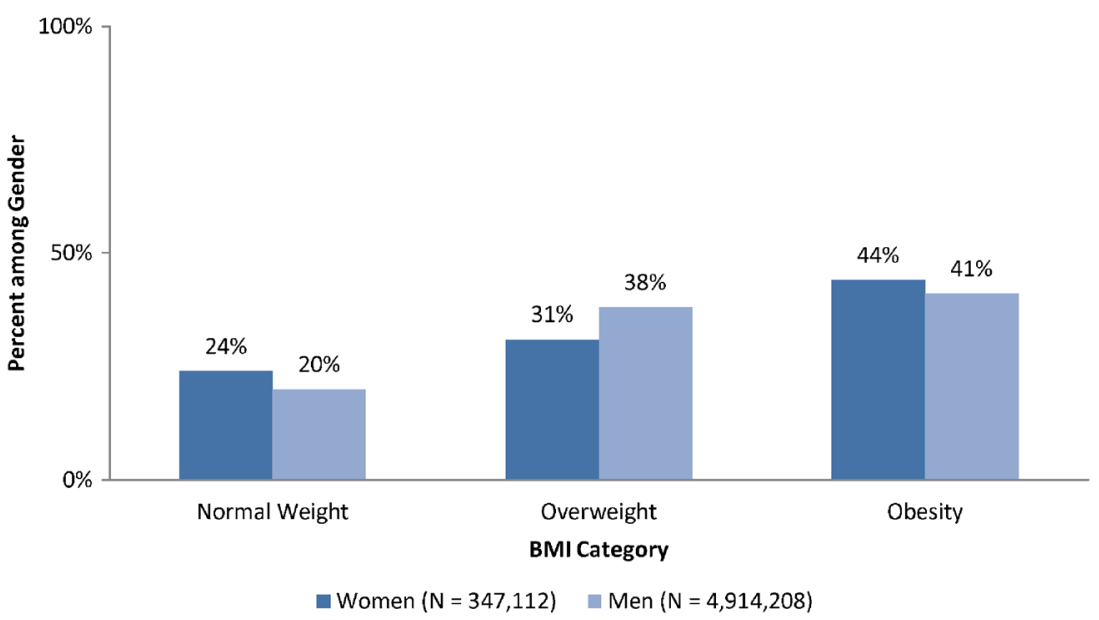

Figure 1 BMI distribution among women and men veteran VHA primary care patients in fiscal year 2014. BMI: body mass index; VHA: Veterans Health Administration; normal weight $\left(18.5 \mathrm{~kg} / \mathrm{m}^{2} \leq \mathrm{BMI}<25 \mathrm{~kg} / \mathrm{m}^{2}\right)$; overweight $\left(25 \mathrm{~kg} / \mathrm{m}^{2} \leq \mathrm{BMI}<30 \mathrm{~kg} / \mathrm{m}^{2}\right) ;$ obesity $(\mathrm{BMI} \geq$ $30 \mathrm{~kg} / \mathrm{m}^{2}$ ). 
Table 1 Prevalence of Obesity Among FY2014 Veteran VHA

Primary Care Patients Nationally and by Subpopulations

\begin{tabular}{|c|c|c|c|c|}
\hline & \multirow{3}{*}{$\begin{array}{l}\text { Row N } \\
\text { Total } \\
\text { sample }\end{array}$} & \multicolumn{3}{|c|}{ Obesity prevalence } \\
\hline & & \multirow{2}{*}{$\begin{array}{l}\text { Total } \\
\text { sample } \\
\mathrm{N}= \\
4,914,208\end{array}$} & \multirow{2}{*}{$\begin{array}{l}\text { Women* } \\
\mathbf{N}= \\
\mathbf{3 4 7 , 1 1 2}\end{array}$} & \multirow{2}{*}{$\begin{array}{l}\text { Men* } \\
N= \\
4,567,09\end{array}$} \\
\hline & & & & \\
\hline Total & $4,914,208$ & $41 \%$ & $44 \%$ & $41 \%$ \\
\hline \multicolumn{5}{|l|}{ Age (years) } \\
\hline $18-44$ & 738,416 & $44 \%$ & $40 \%$ & $46 \%$ \\
\hline $45-64$ & $1,766,767$ & $48 \%$ & $49 \%$ & $48 \%$ \\
\hline $65+$ & $2,409,014$ & $36 \%$ & $37 \%$ & $36 \%$ \\
\hline \multicolumn{5}{|l|}{ Race/ethnicity } \\
\hline White & $3,592,109$ & $41 \%$ & $41 \%$ & $41 \%$ \\
\hline $\begin{array}{l}\text { Black or } \\
\text { African } \\
\text { American }\end{array}$ & 777,692 & $44 \%$ & $51 \%$ & $43 \%$ \\
\hline Hispanic & 279,647 & $43 \%$ & $39 \%$ & $43 \%$ \\
\hline Asian & 40,621 & $24 \%$ & $21 \%$ & $25 \%$ \\
\hline \multicolumn{5}{|l|}{$\begin{array}{l}\text { Hawaiian/ } \\
\text { other Pacific }\end{array}$} \\
\hline $\begin{array}{l}\text { American Indian/ } \\
\text { Alaska Native }\end{array}$ & 28,533 & $47 \%$ & $45 \%$ & $47 \%$ \\
\hline Multiracial & 39,080 & $43 \%$ & $43 \%$ & $43 \%$ \\
\hline $\begin{array}{l}\text { Unknown/ } \\
\text { declined to } \\
\text { state }\end{array}$ & 125,808 & $46 \%$ & $43 \%$ & $47 \%$ \\
\hline \multicolumn{5}{|c|}{ Service-connected disability status ${ }^{\dagger}$} \\
\hline None & $2,421,446$ & $37 \%$ & $41 \%$ & $36 \%$ \\
\hline $0-49 \%$ & $1,122,173$ & $43 \%$ & $43 \%$ & $43 \%$ \\
\hline $50-99 \%$ & $1,005,790$ & $49 \%$ & $46 \%$ & $49 \%$ \\
\hline $100 \%$ & 363,559 & $47 \%$ & $48 \%$ & $47 \%$ \\
\hline \multicolumn{5}{|c|}{ Rural/urban residence } \\
\hline Highly urban & $2,280,998$ & $40 \%$ & $43 \%$ & $40 \%$ \\
\hline Urban & 866,899 & $41 \%$ & $44 \%$ & $41 \%$ \\
\hline Rural & $1,682,082$ & $43 \%$ & $45 \%$ & $43 \%$ \\
\hline Highly rural & 70,756 & $43 \%$ & $42 \%$ & $43 \%$ \\
\hline \multicolumn{5}{|l|}{ Period of service } \\
\hline OEF/OIF/OND & 523,874 & $44 \%$ & $36 \%$ & $45 \%$ \\
\hline $\begin{array}{l}\text { Gulf War I/pre- } \\
\text { OEF/OIF/ } \\
\text { OND }\end{array}$ & 598,070 & $51 \%$ & $47 \%$ & $\mathbf{5 2 \%}$ \\
\hline $\begin{array}{l}\text { Post-Vietnam } \\
\text { War/pre-Gulf } \\
\text { War }\end{array}$ & 556,486 & $48 \%$ & $49 \%$ & $48 \%$ \\
\hline Vietnam War & $2,151,491$ & $44 \%$ & $49 \%$ & $44 \%$ \\
\hline $\begin{array}{l}\text { Post-Korean } \\
\text { War/pre- } \\
\text { Vietnam War }\end{array}$ & 266,078 & $34 \%$ & $39 \%$ & $34 \%$ \\
\hline Korean War & 435,782 & $26 \%$ & $28 \%$ & $26 \%$ \\
\hline $\begin{array}{l}\text { Post-World } \\
\text { War II }\end{array}$ & 14,191 & $21 \%$ & $22 \%$ & $21 \%$ \\
\hline $\begin{array}{l}\text { World War II } \\
\text { or earlier }\end{array}$ & 269,542 & $15 \%$ & $13 \%$ & $15 \%$ \\
\hline Unclassified & 22,533 & $44 \%$ & $43 \%$ & $45 \%$ \\
\hline \multicolumn{5}{|c|}{ Physical health conditions } \\
\hline Sleep apnea & 540,753 & $72 \%$ & $74 \%$ & $72 \%$ \\
\hline Diabetes & $1,325,087$ & $57 \%$ & $68 \%$ & $56 \%$ \\
\hline Hypertension & $2,826,651$ & $46 \%$ & $56 \%$ & $46 \%$ \\
\hline Lipid disorder & $2,597,602$ & $45 \%$ & $52 \%$ & $45 \%$ \\
\hline $\begin{array}{l}\text { Coronary } \\
\text { artery disease }\end{array}$ & 862,749 & $42 \%$ & $47 \%$ & $42 \%$ \\
\hline $\begin{array}{l}\text { Lumbosacral } \\
\text { spine disorder }\end{array}$ & $1,050,310$ & $46 \%$ & $47 \%$ & $45 \%$ \\
\hline $\begin{array}{l}\text { Lower } \\
\text { extremity joint } \\
\text { disorder }\end{array}$ & 933,441 & $\mathbf{5 0 \%}$ & $51 \%$ & $\mathbf{5 0 \%}$ \\
\hline \multicolumn{5}{|c|}{ Mental health conditions } \\
\hline $\begin{array}{l}\text { Major } \\
\text { depressive } \\
\text { disorder }\end{array}$ & 340,976 & $48 \%$ & $49 \%$ & $48 \%$ \\
\hline
\end{tabular}

(continued on next column)
Table 1. (continued)

\begin{tabular}{|c|c|c|c|c|}
\hline & \multirow{3}{*}{$\begin{array}{l}\text { Row N } \\
\text { Total } \\
\text { sample }\end{array}$} & \multicolumn{3}{|c|}{ Obesity prevalence } \\
\hline & & \multirow{2}{*}{$\begin{array}{l}\begin{array}{l}\text { Total } \\
\text { sample }\end{array} \\
\mathrm{N}= \\
\mathbf{4 , 9 1 4 , 2 0 8}\end{array}$} & \multirow{2}{*}{$\begin{array}{l}\text { Women* } \\
\begin{array}{l}\mathrm{N}= \\
\mathbf{3 4 7 , 1 1 2}\end{array}\end{array}$} & \multirow{2}{*}{$\begin{array}{l}\text { Men* } \\
\mathrm{N}= \\
\mathbf{4 , 5 6 7 , 0 9 6}\end{array}$} \\
\hline & & & & \\
\hline $\begin{array}{l}\text { Bipolar } \\
\text { disorder }\end{array}$ & 123,252 & $47 \%$ & $49 \%$ & $46 \%$ \\
\hline PTSD & 675,921 & $47 \%$ & $46 \%$ & $47 \%$ \\
\hline $\begin{array}{l}\text { Anxiety } \\
\text { disorder }\end{array}$ & 528,765 & $42 \%$ & $42 \%$ & $42 \%$ \\
\hline Schizophrenia & 77,747 & $42 \%$ & $56 \%$ & $41 \%$ \\
\hline $\begin{array}{l}\text { Drug use } \\
\text { disorder }\end{array}$ & 232,876 & $33 \%$ & $36 \%$ & $33 \%$ \\
\hline $\begin{array}{c}\text { Alcohol use } \\
\text { disorder }\end{array}$ & 377,873 & $34 \%$ & $35 \%$ & $34 \%$ \\
\hline $3+$ Conditions & $2,348,005$ & $\mathbf{5 0 \%}$ & $54 \%$ & $49 \%$ \\
\hline
\end{tabular}

Boldface font in an obesity prevalence column indicates subgroup prevalence $\geq 5 \%$ above overall obesity prevalence for the total cohort (41\%).

Obesity: BMI $\geq 30+\mathrm{kg} / \mathrm{m}^{2}$; FY2014: fiscal year 2014; VHA: Veterans Health Administration; OEF/OIF/OND: Operation Enduring Freedom/ Operation Iraqi Freedom/Operation New Dawn; PTSD: post-traumatic stress disorder.

*Represents proportion among only that gender.

${ }^{\dagger}$ Designates presence and rating of an injury or illness incurred or aggravated during military service, rated from 0 to $100 \%$.

Includes physical and/or mental health conditions

Given the high obesity prevalence among VHA primary care patients, a population health approach to weight management is warranted. However, while overall obesity prevalence is high in the VHA, it does not affect all equally: obesity prevalence among several veteran subpopulations was higher than mean obesity prevalence by at least $5 \%$ (which has been used as a clinically meaningful threshold ${ }^{8}$ ). Therefore, in its efforts to reduce obesity within the overall population, the VHA must remain vigilant to avoid unintentionally increasing disparities. This may require approaches such as determining whether subpopulations with the highest obesity prevalence use weight management programs at rates commensurate with their risk. Existing work offers some information; for example, veterans with serious mental illness or depressive disorders, ${ }^{21}$ veterans with higher service-connected disability status, ${ }^{22}$, 23 and veterans with more health conditions ${ }^{23,} 24$ are more likely to use MOVE!, one of the VHA's weight management programs. ${ }^{24,}{ }^{25}$ Conversely, despite high obesity prevalence among younger veterans, they have low MOVE! use. $^{23,}{ }^{24}$ Additional work is needed, as black women veterans and women veterans with schizophrenia have high obesity prevalence, but analyses of weight loss treatment use are rarely stratified by gender. Moreover, there are few data on disparities in the use of VHA programs other than MOVE!.

Other subpopulations with excess obesity prevalence also merit attention, including Native Hawaiian/other Pacific Islander and American Indian/Alaska Native veterans. These groups have not historically been the focus of health-related 
research, ${ }^{26}$ despite the fact that American Indian/Alaska Native veterans served in the military post-9/11 at higher rates than other racial/ethnic groups. ${ }^{27}$ In addition, obesity was very common among men veterans age 18-44. It is notable that obesity was far more common among these men than among men age 20-39 in the general US population $\left(46 \%\right.$ vs. $\left.32 \%{ }^{1}\right)$. Given their long horizon for VHA care, the benefits of behavioral interventions (e.g., MOVE! use is associated with decreased diabetes incidence ${ }^{28}$ ), and the fact that men veterans are less likely to use MOVE! than women veterans, ${ }^{23,}{ }^{24}$ understanding and increasing weight loss treatment engagement in this group could prevent the onset of costly and debilitating chronic conditions later in life.

Future Research. While tailoring weight loss treatments to populations with the highest obesity prevalence could help the VHA prevent health disparities, it is a complex undertaking. Approaches may appear promising in one setting, but not in another: a weight management program tailored for patients with serious mental illness at Kaiser Permanente was associated with more weight loss than was usual care, ${ }^{29}$ whereas a trial investigating VHA's MOVE! program tailored for veterans with serious mental illness had null results. ${ }^{30}$ In addition, work on cultural tailoring can be limited by a lack of clear methods for operationalizing the tailoring so that interventions can be optimally and empirically tested. $^{31}$

In light of these complexities, well-designed VHA research in this area could have a broad impact. For example, the VHA, with its mostly male patient population, represents an excellent setting in which to conduct weight management research among men, a population that may benefit from tailored approaches (e.g., individual as opposed to group treatment), but that is underrepresented in existing work. ${ }^{32-34}$ With its diverse patient population, the VHA is also well-positioned to move beyond unidimensional analyses of disparities, and instead examine disparities among patients at the intersection of historically disadvantaged groups. ${ }^{35}$

Several other intriguing areas for future work emerge from our findings, for example, understanding why Asian veterans using the VHA have such high obesity prevalence compared to other Asian Americans ( $24 \%$ vs. $13 \%{ }^{1}$ ). In addition, given the correlation between some mental health conditions and excess weight, ${ }^{36-39}$ it is worth investigating whether the high prevalence of mental health conditions among VHA patients ${ }^{5}$ contributes to the higher rate of obesity in the VHA compared to the general US population. Considering the high need and associated high costs of patients with multimorbid conditions, ${ }^{40}$ the relationship between obesity and multimorbidity also merits further research, particularly because conditions in the present analyses were selected based on their associations with obesity and/or high prevalence among VHA-using veterans.
Limitations. This paper did not attempt to explore mechanisms for observed differences in obesity prevalence between groups. For example, we did not assess veterans' bariatric surgery history, their use of medications that facilitate weight loss (directly or as a side effect), or their use of medications that promote weight gain (including many psychiatric medications, relevant to the large group with comorbid mental health conditions). Any of these factors could have contributed to between-group differences if there was differential use across subpopulations. Nor did we have information on income or education, which could also be drivers of some observed differences. Further, with crosssectional data, we cannot draw causal conclusions (e.g., whether musculoskeletal conditions cause obesity, or the reverse).

Other limitations include the fact that, at the individual level, BMI is an imperfect measure of future health risk, ${ }^{41}$ particularly when comparing across race and ethnicity ${ }^{42}$ or when examining older patients who may have lower than average muscle mass. ${ }^{43}$ In addition, our use of a wide date range for assessing height could have led to an underestimation of BMI among some older veterans, given declines in height with advancing age. ${ }^{44}$ Our method of identifying comorbid conditions means that, for patients who joined the VHA late in FY2014, there may have been less opportunity for the detection of a medical condition that was present. Additionally, findings may not be generalizable to the $10 \%$ of veteran VHA patients not using primary care, ${ }^{5}$ or to the $\sim 15$ million veterans not using the $\mathrm{VHA}^{45}$

Strengths. Despite these limitations, our methods have several strengths. For example, they allowed us to include $98 \%$ of all VHA primary care patients in analyses, minimizing potential selection bias. The large-scale and national scope of this work is particularly valuable, given known geographic variability in obesity prevalence. ${ }^{46}$ Furthermore, since the bulk of prior weight management research has focused on women (especially white women $^{32,33}$ ), our ability to examine obesity in several populations that previously received little attention adds to the general scientific literature in this field. An additional strength is that obesity case-finding in this paper relied on BMI values calculated using height and weight from the VHA national electronic health record rather than ICD-9 diagnoses. Finally, while BMI cannot perfectly measure health, it is consistently associated with adverse outcomes, ${ }^{3}$ and is therefore a valid way to assess the population at risk for obesity-related health conditions within the VHA.

Conclusions. The high prevalence of overweight and obesity in our cohort supports the VHA's continued investment in deploying effective weight management programs, as losing just 4-7 pounds can improve health outcomes. ${ }^{2}$ Efforts should focus on increasing engagement in the variety of weight 
management treatments offered by the VHA, including inperson treatments (e.g., MOVE!), telephone coaching, weight loss medications, and bariatric surgery. Options that allow for flexible scheduling may have particular value, due to the high prevalence of obesity among veterans of working age, who may need after-hours care.

Given the high obesity prevalence among the general US population, the results of such efforts could have a broad impact, especially in light of calls for an increased focus on population health management in the United States. ${ }^{47-49}$ For veterans, the VHA's weight management initiatives have the potential to avert long-term morbidity arising from obesityrelated conditions. High-risk groups in the VHA - such as black women veterans, women veterans with schizophrenia, younger veterans, Native Hawaiian/other Pacific Islander veterans, and American Indian/Alaska Native veterans - as well as high-risk groups in the general US population, may require particular attention to ensure that systems improvement efforts at the population level do not inadvertently increase health disparities.

Corresponding Author: Jessica Y. Breland, PhD; VA HSR\&D Center for Innovation to Implementation (Ci2i), VA Palo Alto Health Care System, 795 Willow Road (MPD-152), Menlo Park, CA 94025, USA (e-mail: jessica.breland@va.gov).

\section{Compliance with Ethical Standards:}

Contributors: The authors would like to thank Mr. Eric Berg, Dr. Hui Wang, Ms. Elon Hailu, and Mr. Jonathan Mendoza for technical expertise, and Dr. Jazmin Reyes-Portillo for her review of the manuscript.

Funders: This program evaluation work was supported by Women's Health Services in the VA Central Office through the Women's Health Evaluation Initiative, and by VHA's Office of Health Equity through the Office of Health Equity-Quality Enhancement Research Initiative (QUERI) Partnered Evaluation Center. Dr. Breland was supported by the VA Office of Academic Affiliations and Health Services Research and Development Service (HSR\&D) funds and a VA HSR\&D Career Development Award (CDA 15-257) at the VA Palo Alto. Dr. Hoggatt was supported by a Department of Veterans Affairs HSR\&D/QUERI Career Development Award (CDA 11-261) at the Greater Los Angeles VA. The views expressed in this article are those of the authors and the contents do not represent the views of the Department of Veterans Affairs or the United States government.

Conflict of Interest: All authors report no conflicts of interest.

\section{REFERENCES}

1. Flegal KM, Kruszon-Moran D, Carroll MD, Fryar CD, Ogden CL. Trends in Obesity Among Adults in the United States, 2005 to 2014. J Am Med Assoc. 2016;315(21):2284-91.

2. Expert Panel Members, Jensen M, Ryan D, Donato $\mathbf{K}$ et al. Executive summary: Guidelines (2013) for the management of overweight and obesity in adults. Obesity (Silver Spring). 2014;22(Suppl 2):S5-39.

3. Flegal KM, Kit BK, Orpana H, Graubard BI. Association of all-cause mortality with overweight and obesity using standard body mass index categories: a systematic review and meta-analysis. J Am Med Assoc. 2013;309(1):71-82
4. The Management of Overweight and Obesity Working Group. VA/DOD Clinical practice guidelines for screening and management of overweight and obesity. Version 2.0. Washington, DC: Department of Veteran Affairs, Department of Defense., 2014.

5. Frayne S, Phibbs C, Saechao F, et al. Sourcebook: Women Veterans in the Veterans Health Administration. Volume 3. Sociodemographics, Utilization, Costs of Care, and Health Profile. Washington, DC: Women's Health Evaluation Initiative, Women's Health Services, Veterans Health Administration, Department of Veterans Affairs, 2014. Available from: http://www.womenshealth.va.gov/docs/Sourcebook_Vol_3_FINAL.pdf and http://www.womenshealth.va.gov/WOMENSHEALTH/sourcebookvol3onlineappendix.asp.

6. Noel PH, Copeland LA, Perrin RA, et al. VHA Corporate Data Warehouse height and weight data: opportunities and challenges for health services research. J Rehabil Res Dev. 2010;47(8):739-50.

7. Veterans Health Administration Office of Health Equity. VHA Health Equity Action Plan, 2016. Available from: http://www.va.gov/HEALTHEQUITY/docs/Health_Equity_Action_Plan_Final_Rev03042016.pdf.

8. VA Office of Health Equity. National Veteran Health Equity Report-FY2013. Washington, DC: US Department of Veterans Affairs, 2016. Available from: http://www.va.gov/healthequity/NVHER.asp.

9. Washington DL, Bean-Mayberry B, Hamilton AB, Cordasco KM, Yano EM. Women veterans' healthcare delivery preferences and use by military service era: findings from the National Survey of Women Veterans. J Gen Intern Med. 2013;28(Suppl 2):S571-6.

10. Veterans Health Administration Office of Health Equity. Timeline of U.S. Period of Service Eras. 2016. http://www.va.gov/HEALTHEQUITY/docs/ Period_of_Service_Timeline_OHE10212016.pdf. Accessed 10/28/16 2016.

11. Ogden CL, Carroll MD, Fryar CD, Flegal KM. Prevalence of obesity among adults and youth: United States, 2011-2014. NCHS Data Brief. 2015(2 19): 1-8

12. Ogden CL, Carroll MD, Kit BK, Flegal KM. Prevalence of childhood and adult obesity in the United States, 2011-2012. JAMA. 2014;311(8):806-14.

13. Smith TJ, Marriott BP, Dotson L, et al. Overweight and obesity in military personnel: sociodemographic predictors. Obesity (Silver Spring). 2012;20(7): 1534-8.

14. Eibner C, Krull H, Brown KM, et al. Current and projected characteristics and unique health care needs of patient population served by the Department of Veterans Affairs. Santa Monica, CA: RAND Corporation, 2015. Available from: http://www.rand.org/pubs/research_reports/ RR1165z1.html

15. Frayne SM, Parker VA, Christiansen CL, et al. Health status among 28,000 women veterans: The VA Women's Health Program Evaluation Project. J Gen Intern Med. 2006;21(Suppl 3):S40-6.

16. Luncheon C, Zack M. Health-related quality of life among US veterans and civilians by race and ethnicity. Prev Chronic Dis. 2012;9:E108.

17. Wilson NJ, Kizer KW. The VA health care system: an unrecognized national safety net. Health Aff (Millwood). 1997;16(4):200-4.

18. Yu W, Ravelo A, Wagner TH, et al. Prevalence and costs of chronic conditions in the VA health care system. Med Care Res Rev. 2003;60(3 Suppl): 146s-67s

19. Dursa EK, Barth SK, Bossarte RM, Schneiderman AI. Demographic, Military, and Health Characteristics of VA Health Care Users and Nonusers Who Served in or During Operation Enduring Freedom or Operation Iraqi Freedom, 2009-2011. Public Health Reports. 2016:0033354916676279.

20. Nelson KM, Starkebaum GA, Reiber GE. Veterans using and uninsured veterans not using Veterans Affairs (VA) health care. Public Health Rep. 2007;122(1):93-100.

21. Littman AJ, Damschroder LJ, Verchinina L, et al. National evaluation of obesity screening and treatment among veterans with and without mental health disorders. Gen Hosp Psychiatry. 2015;37(1):7-13.

22. Funderburk JS, Arigo D, Kenneson A. Initial engagement and attrition in a national weight management program: demographic and health predictors. Transl Behav Med. 2016;6(3): 358-68.

23. McVay MA, Yancy WS Jr, Vijan S, et al. Obesity-related health status changes and weight-loss treatment utilization. Am J Prev Med. 2014;46(5):465-72.

24. Littman AJ, Boyko EJ, McDonell MB, Fihn SD. Evaluation of a weight management program for veterans. Prev Chronic Dis. 2012;9:E99.

25. Kahwati LC, Lance TX, Jones KR, Kinsinger LS. RE-AIM evaluation of the Veterans Health Administration's MOVE! Weight Management Program. Transl Behav Med. 2011;1(4):551-60.

26. Fialkowski MK, Okoror TA, Boushey CJ. The relevancy of communitybased methods: using diet within Native American and Alaska Native adult populations as an example. Clin Transl Sci. 2012;5(3):295-300. 
27. National Center for Veterans Analysis and Statistics. American Indian and Alaska Native Veterans: 2013 American Community Survey. Washington, DC: US Department of Veterans Affairs, 2015. Available from: http://www.va.gov/vetdata/docs/SpecialReports/AIANReport2015.pdf.

28. Jackson SL, Long $\mathbf{Q}$, Rhee MK, et al. Weight loss and incidence of diabetes with the Veterans Health Administration MOVE! lifestyle change programme: an observational study. Lancet Diabetes Endocrinol. 2015;3(3):173-80.

29. Green CA, Yarborough BJH, Leo MC, et al. The STRIDE weight loss and lifestyle intervention for individuals taking antipsychotic medications: a randomized trial. Am J Psychiatry. 2015;172(1):71-81.

30. Goldberg RW, Reeves G, Tapscott S, et al. "MOVE!" Outcomes of a weight loss program modified for veterans with serious mental illness. Psychiatr Serv. 2013;64(8):737-44.

31. Kumanyika SK, Whitt-Glover MC, Haire-Joshu D. What works for obesity prevention and treatment in black Americans? Research direc tions. Obes Rev. 2014;15(Suppl 4):204-12.

32. Pagoto SL, Schneider KL, Oleski JL, Luciani JM, Bodenlos JS, Whited MC. Male inclusion in randomized controlled trials of lifestyle weight loss interventions. Obesity (Silver Spring). 2012;20(6):1234-9.

33. Robertson C, Avenell A, Boachie C, et al. Should weight loss and maintenance programmes be designed differently for men? A systematic review of long-term randomised controlled trials presenting data for men and women: The ROMEO project. Obes Res Clin Pract. 2016;101(1): 7084.

34. Young MD, Morgan PJ, Plotnikoff RC, Callister R, Collins CE. Effectiveness of male-only weight loss and weight loss maintenance interventions: a systematic review with meta-analysis. Obes Rev. 2012;13(5):393-408.

35. Jackson JW, Williams DR, VanderWeele TJ. Disparities at the intersection of marginalized groups. Soc Psychiatry Psychiatr Epidemiol. 2016;51(10):1349-59.

36. Cooper SJ, Reynolds GP, Barnes T, et al. BAP guidelines on the management of weight gain, metabolic disturbances and cardiovascular risk associated with psychosis and antipsychotic drug treatment. J Psychopharmacol. 2016;30(8):717-48.

37. Maguen S, Madden E, Cohen B, et al. The relationship between body mass index and mental health among Iraq and Afghanistan veterans. J Gen Intern Med. 2013;28(Suppl 2):S563-70.

38. Luppino FS, de Wit LM, Bouvy PF, et al. Overweight, obesity, and depression: A systematic review and meta-analysis of longitudinal studies. Arch Gen Psychiatry. 2010;67(3):220-9.
39. Ringen PA, Engh JA, Birkenaes AB, Dieset I, Andreassen OA. Increased mortality in schizophrenia due to cardiovascular disease-a non-systematic review of epidemiology, possible causes, and interventions. Front Psychiatry. 2014;5:137.

40. Zulman DM, Yoon J, Cohen DM, Wagner TH, Ritchie C, Asch SM. Multimorbidity and health care utilization among high-cost patients: Implications for care coordination. J Gen Intern Med. 2013;28(1):S123.

41. Roberson LL, Aneni EC, Maziak W, et al. Beyond BMI: The "Metabolically healthy obese" phenotype \& its association with clinical/ subclinical cardiovascular disease and all-cause mortality-a systematic review. BMC Public Health. 2014;14(1):1-12.

42. Boffetta $\mathbf{P}, \mathbf{M c L e r r a n} \mathbf{D}$, Chen $\mathbf{Y}$, et al. Body mass index and diabetes in Asia: a cross-sectional pooled analysis of 900,000 individuals in the Asia cohort consortium. PLoS One. 2011;6(6):e19930.

43. Rothman KJ. BMI-related errors in the measurement of obesity. Int $\mathrm{J}$ Obes (Lond). 2008;32(Suppl 3):S56-9.

44. Sorkin JD, Muller DC, Andres R. Longitudinal change in height of men and women: implications for interpretation of the body mass index: the Baltimore Longitudinal Study of Aging. Am J Epidemiol. 1999;150(9):969-77.

45. National Center for Veterans Analysis and Statistics. Veteran Population Tables. http://www.va.gov/vetdata/veteran_population.asp. Accessed 6/14/16 2016.

46. Myers CA, Slack T, Martin CK, Broyles ST, Heymsfield SB. Regional disparities in obesity prevalence in the United States: A spatial regime analysis. Obesity (Silver Spring). 2015;23(2):481-7.

47. Berwick DM, Nolan TW, Whittington J. The triple aim: care, health, and cost. Health Aff (Millwood). 2008;27(3):759-69.

48. Eggleston EM, Finkelstein JA. Finding the role of health care in population health. JAMA. 2014;311(8):797-8.

49. National Academies of Sciences, Engineering, and Medicine. Advancing the science to improve population health: Proceedings of a workshop. Washington, DC: The National Academies Press; 2016. Available from http://www.nationalacademies.org/hmd/Reports/2016/Advancing-theScience-to-Improve-Population-Health-Proceedings.aspx. 